Eur. J. Clin. Chem. Clin. Biochem.

Vol. 29, 1991, pp. $185-188$

(C) 1991 Walter de Gruyter \& Co.

Berlin - New York

\title{
Urine Screening in Outdoor Volunteers: Day Versus Night Versus 24 Hour Collection
}

By A.-N. Khalaf ${ }^{1}$, J. Böcker ${ }^{2}$, L. Kerp ${ }^{1}$ and K.-G. Petersen ${ }^{1}$

1 Abteilung Klinische Endokrinologie

${ }^{2}$ Abteilung Klinische Chemie, Medizinische Universitätsklinik, Klinikum der Albert-Ludwigs-Universität, Freiburg i. Br., Germany

(Received July 13/December 3, 1990)

Summary: Urine constituents were measured in 12 healthy outdoor volunteers on four occasions within a month. Day, night, and 24 hour collection periods were compared. Measurements made on the four occasions did not differ. The amount of water, creatinine, electrolytes, proteins, and enzymes were higher during the day (up to three fold, $p$ always $<0.05$ ), while equal amounts of amino acids were excreted in the day and the night period. A comparison of all values from all individuals for all four sampling occasions showed that the variation was lowest in the 24 hour samples. Relating the values to creatinine did not consistently reduce the variation. Twenty-four hour samples correlated better with the day than with the night samples. Day and night samples did not correlate.

Twenty-four hour collection is superior to day or night collection in healthy outdoor volunteers. Based on the normal variation of values found in the present study, criteria for suspected kidney damage and therefore for the withdrawal of drugs in pharmacological studies can be defined for each collection period.

\section{Introduction}

The clinical investigation of drugs for possible side effects on the kidneys and for quantitation of excretion often uses the screening of urine in outdoor volunteers. Collection of 24 hour samples of urine is a burden on the daily lives of volunteers. A shorter collection time could improve the reproducibility. The 12 hour day period or the 12 hour night period might be useful, thereby including or excluding effects of physical activity. In order to test chemicals for possible nephrotoxicity, criteria are required for the early recognition of kidney dysfunction, so that the study can be terminated before damage occurs. A prospective definition of such criteria should be based on a knowledge of the normal variation of values for urine constituents in any chosen collection period.

We have investigated the variation range of measurements and the reliability of three collection periods ( 24 hours, 12 hours day, 12 hours night) regarding the excretion of electrolytes, proteins, enzymes and amino acids in healthy outdoor volunteers. The effect of relating the data to urine creatinine $(1,2)$ was determined. As in pharmacological studies, urines were collected on days $0,1,14$ and 28 . The data can be used to define withdrawal criteria in study protocols.

\section{Materials and Methods}

Twelve healthy male volunteers (age 18 to 48 years, height 174 to $192 \mathrm{~cm}$, body weight 71 to $89 \mathrm{~kg}$ ) gave informed consent. They continued their usual diet, work and lifestyle. Urines were collected on days $0,1,14$ and 28 from 8 a.m. to 8 p.m. and from 8 p. m. to $8 \mathrm{a} . \mathrm{m}$. on the next day. Samples were taken from the urines collected during the day and the night period. A whole day urine sample was produced by mixing aliquots of day and night urine according to the volumes. Samples were kept frozen at $-20^{\circ} \mathrm{C}$.

Urine concentrations of immunoglobulin $G$, albumin, $\alpha_{1}-g l y-$ coprotein, lysozyme, and $\beta_{2}$-microglobulin were determined by ELISA (3). Sodium, potassium, chloride, creatinine, $\gamma$-gluta- 
myltransferase, and alkaline phosphatase were determined with a Hitachi 737 automatic analyser (Boehringer Mannheim, Mannheim, Germany). N-Acetyl- $\beta$ - $D$-glucosaminidase was determined colorimetrically with the NAG Farbtest ${ }^{(t)}$ (Bochringer Mannheim, Mannhein, Germany). Amino acids were measured on an LKB 4151 alpha plus amino acid analyser (LKB, Uppsala, Sweden).

Results are expressed as mean \pm SEM. Statistical calculations were done with Asystant ${ }^{\text {id }}$ software (Asyst Technologies, Rochester, N. Y., USA) on a Siemens PC (Siemens AG, Munich, Germany).

\section{Results}

Urines of 12 outdoor volunteers were collected from 8 a.m. to 8 p.m. and from 8 p.m. to 8 a.m. on days $0,1,14$ and 28 of the study. Aliquots were taken from the day collection, the night collection and from a mixture of both (24 hour period). Comparison of the values for each parameter revealed no differences in the amounts excreted between any two days as evaluated in Student's t-test for paired samples. Measurements of day 0 are shown in table 1 . The amount of creatinine excreted during the day was $9.9 \%$ higher than in the night $(p<0.05)$. The, excretion of serum electrolytes, serum proteins and enzymes was higher during the day (up to two- or threefold, $p$ always $<0.05$ ). There was no day-night difference in the amino acid excretion. The creatinine clearances were $117.2 \pm 4.1 \mathrm{ml} / \mathrm{min}(24 \mathrm{~h}), 123.2 \pm 6.4 \mathrm{ml} / \mathrm{min}(12 \mathrm{~h}$ day), and $111.1 \pm 4.6 \mathrm{ml} / \mathrm{min}$ ( $12 \mathrm{~h} \mathrm{night)}$.

Each parameter was analysed for variation between individuals on one sampling occasion (tab. 2) and

Tab. 1. Quantitative analysis of urines in twelve outdoor volunteers: Day 0 (mean $\pm \mathrm{SEM}$ ); $24 \mathrm{~h}$ versus $12 \mathrm{~h}$ day versus $12 \mathrm{~h}$ night samples.

\begin{tabular}{|c|c|c|c|c|c|c|c|c|}
\hline \multirow{3}{*}{ Water : } & \multirow{3}{*}{$\begin{array}{l}(\mathrm{ml}) \\
(\mathrm{mg})\end{array}$} & \multicolumn{2}{|l|}{24 hour } & \multicolumn{2}{|c|}{12 hour day } & & \multicolumn{2}{|c|}{12 hour night } \\
\hline & & 1550 & \pm 203 & 929 & \pm 154 & & 621 & \pm 74 \\
\hline & & 169.3 & \pm 17.0 & 88.6 & $\pm \quad 11.6$ & & 80.7 & \pm 9.7 \\
\hline Sodium & (mmol) & 166.3 & \pm 15.4 & 93.4 & \pm 10.1 & & 72.9 & \pm 9.0 \\
\hline Potassium & (mmol) & 76.5 & 8.3 & 53.8 & 4.6 & & 22.7 & \pm 3.8 \\
\hline Chloride & (mmol) & 168.5 & \pm 17.2 & 104.8 & \pm 12.4 & & 63.7 & \pm 7.4 \\
\hline Immunoglobulin $\mathrm{G}$ & $(\mathrm{mg})$ & 5.13 & $\pm \quad 0.55$ & 3.36 & 0.61 & & 1.77 & \pm 0.35 \\
\hline Albumin & (mg) & 6.40 & 1.58 & 4.03 & 1.27 & & 2.37 & \pm 0.63 \\
\hline$\alpha_{1}$-Glycoprotein & $(\mu \mathrm{g})$ & 897.5 & \pm 205.0 & 655.1 & \pm 187.7 & & 242.4 & $\pm 52: 0$ \\
\hline Lysozyme & $(\mu \mathrm{g})$ & 244.0 & \pm 22.4 & 130.8 & \pm 19.2 & & 113.2 & \pm 7.1 \\
\hline$\beta_{2}$-Microglobulin & $(\mu \mathrm{g})$ & 395.0 & \pm 78.7 & 261.3 & \pm 57.4 & & 133.7 & \pm 34.8 \\
\hline Alkaline phosphatase & (U) & 1.42 & 0.29 & 0.84 & 0.21 & & 0.58 & \pm 0.13 \\
\hline$\gamma$-Glutamyltransferase & (U) & 4.37 & 0.22 & 3.12 & 0.18 & & 1.25 & \pm 0.12 \\
\hline$N$-Acetyl- $\beta$ - $D$-glucosaminidase & (U) & 1.95 & 0.22 & 1.06 & 0.20 & & 0.89 & \pm 0.07 \\
\hline Aspartic acid & $(\mu \mathrm{mol})$ & 231.6 & \pm 35.4 & 105.6 & \pm 14.9 & & 126.0 & \pm 20.6 \\
\hline Serine & $(\mu \mathrm{mol})$ & 285.4 & \pm 46.2 & 139.9 & \pm 31.7 & & 145.5 & \pm 20.0 \\
\hline Tyrosine & $(\mu \mathrm{mol})$ & 141.4 & \pm 17.5 & 70.2 & 9.7 & & 71.2 & \pm 10.8 \\
\hline Lysine & $(\mu \mathrm{mol})$ & 128.3 & \pm 26.4 & 62.4 & \pm 12.4 & $\ldots$ & 65.9 & \pm 17.6 \\
\hline Glycine & $(\mu \mathrm{mol})$ & 994.8 & \pm 99.0 & 540.4 & \pm 68.9 & & 454.4 & \pm 60.5 \\
\hline Phenylalanine & $(\mu \mathrm{mol})$ & 80.9 & \pm 13.0 & 42.7 & 8.44 & & 38.2 & \pm 7.4 \\
\hline
\end{tabular}

Tab. 2. Variation coefficients of urinary excretion parameters measured in 24 hour, 12 hour day and 12 hour night samples of twelve outdoor volunteers on one day (mean of days $0,1,24$ and 28 of the study \pm SEM).

\begin{tabular}{llll}
\hline & 24 hour & 12 hour day & 12 hour night \\
\hline Water & $0.31 \pm 0.04$ & $0.41 \pm 0.09$ & $0.49 \pm 0.07$ \\
Creatinine & $0.23 \pm 0.04$ & $0.34 \pm 0.06$ & $0.33 \pm 0.04$ \\
Sodium & $0.34 \pm 0.06$ & $0.47 \pm 0.09$ & $0.48 \pm 0.06$ \\
Potassium & $0.38 \pm 0.03$ & $0.44 \pm 0.07$ & $0.52 \pm 0.05$ \\
Chloride & $0.38 \pm 0.05$ & $0.45 \pm 0.08$ & $0.62 \pm 0.03$ \\
Immunoglobulin G & $0.47 \pm 0.05$ & $0.59 \pm 0.04$ & $0.97 \pm 0.12$ \\
Albumin & $0.76 \pm 0.08$ & $0.87 \pm 0.12$ & $0.96 \pm 0.17$ \\
$\alpha_{1}$-Glycoprotein & $0.85 \pm 0.14$ & $0.98 \pm 0.16$ & $0.91 \pm 0.16$ \\
Lysozyme & $0.49 \pm 0.08$ & $0.68 \pm 0.17$ & $0.65 \pm 0.11$ \\
B2-Microglobulin & $0.72 \pm 0.07$ & $0.72 \pm 0.03$ & $1.14 \pm 0.14$ \\
Alkaline phosphatase & $0.73 \pm 0.08$ & $0.89 \pm 0.13$ & $0.87 \pm 0.15$ \\
$\gamma$-Glutamyltransferase & $0.43 \pm 0.08$ & $0.81 \pm 0.21$ & $0.73 \pm 0.08$ \\
N-Acetyl- $\beta-D$-glucosaminidase & $0.54 \pm 0.12$ & $0.53 \pm 0.10$ & $0.78 \pm 0.25$ \\
Aspartic acid & $0.35 \pm 0.06$ & $0.37 \pm 0.01$ & $0.54 \pm 0.09$ \\
Serine & $0.44 \pm 0.12$ & $0.59 \pm 0.15$ & $0.46 \pm 0.03$ \\
Tyrosine & $0.41 \pm 0.01$ & $0.41 \pm 0.03$ & $0.60 \pm 0.01$ \\
Lysine & $0.75 \pm 0.04$ & $0.91 \pm 0.25$ & $0.90 \pm 0.06$ \\
Glycine & $0.33 \pm 0.01$ & $0.41 \pm 0.01$ & $0.52 \pm 0.01$ \\
Phenylalanine & $0.41 \pm 0.10$ & $0.46 \pm 0.14$ & $0.58 \pm 0.06$ \\
\hline
\end{tabular}


within the same individual on all 4 sampling occasions (tab. 3). The quantitative measurements were most reliable in the 24 hour samples, as indicated by the variation coefficients. The night period was not better than the day period. The above was true between individuals (tab. 2) and in the same individual (tab. 3). Data from the measurements of the twenty amino acids varied uniformly so that only six of them are represented here.

Urine creatinine is often used to relate urine constituents to the glomerulum filtrate $(1,2)$. The metabolite/creatinine ratio was calculated for the urine analytes, except for the enzymes which are of tubular origin. As shown in table 4, the variation of the values for amino acids was decreased $(p<0.05)$ for 24 hours as well as for day and night sampling. There was no consistent decrease in the variation of the values for proteins and electrolytes. Intraindividual calculations produced comparable results.

The effect of shortening the collection period was also analysed by correlating the data from the two 12 hour and the 24 hour samples (tab. 5). There was good correlation between the 24 hour samples and the 12 hour samples. The 12 hour day period measurements of proteins, creatinine and electrolytes correlated better than the 12 hour night measurements with the whole day samples. An unsatisfactory correlation was found between the data from day and night periods.

\section{Discussion}

Twelve and 24 hour urine collection periods were compared in healthy outdoor volunteers with regard to the reliability and variation of measurements of urine constituents still to be considered within normal range. The study design was similar to a common 4 weeks protocol for the assessment of drug effects and side effects on the kidneys, with urine collections on days $0,1,14$ and 28 . Comparable data were obtained on all four collecting occasions. This shows that outdoor volunteers with no restrictions on their daily lives produce reliable data.

Tab. 3. Variation coefficients of urinary excretion parameters measured in 24 hour, 12 hour day and 12 hour night samples on days $0,1,14$ and 28 of the study in each individual (mean of twelve volunteers $\pm S E M$ ).

\begin{tabular}{llll}
\hline & 24 hour & 12 hour day & 12 hour nightt \\
\hline Water & $0.29 \pm 0.03$ & $0.39 \pm 0.05$ & $0.48 \pm 0.06$ \\
Creatinine & $0.19 \pm 0.03$ & $0.28 \pm 0.04$ & $0.28 \pm 0.05$ \\
Sodium & $0.30 \pm 0.05$ & $0.39 \pm 0.07$ & $0.43 \pm 0.05$ \\
Potassium & $0.26 \pm 0.03$ & $0.31 \pm 0.04$ & $0.42 \pm 0.04$ \\
Chloride & $0.33 \pm 0.05$ & $0.37 \pm 0.06$ & $0.58 \pm 0.06$ \\
Immunoglobulin G & $0.38 \pm 0.03$ & $0.50 \pm 0.05$ & $0.71 \pm 0.09$ \\
Transferrin & $0.37 \pm 0.04$ & $0.58 \pm 0.07$ & $0.55 \pm 0.06$ \\
Albumin & $0.46 \pm 0.08$ & $0.55 \pm 0.08$ & $0.71 \pm 0.08$ \\
$\alpha_{1}$-Glycoprotein & $0.43 \pm 0.05$ & $0.53 \pm 0.07$ & $0.71 \pm 0.09$ \\
Lysozyme & $0.73 \pm 0.07$ & $0.82 \pm 0.06$ & $0.75 \pm 0.09$ \\
B-Microglobulin & $0.52 \pm 0.06$ & $0.53 \pm 0.06$ & $0.94 \pm 0.12$ \\
Alkaline phosphatase & $0.40 \pm 0.10$ & $0.54 \pm 0.16$ & $0.76 \pm 0.19$ \\
$\gamma$-Glutamyltransferase & $0.86 \pm 0.08$ & $0.95 \pm 0.08$ & $0.86 \pm 0.11$ \\
N-Acetyl- $\beta-D$-glucosaminidase & $0.40 \pm 0.04$ & $0.53 \pm 0.03$ & $0.57 \pm 0.05$ \\
Aspartic acid & $0.24 \pm 0.06$ & $0.29 \pm 0.07$ & $0.40 \pm 0.09$ \\
Serine & $0.25 \pm 0.06$ & $0.39 \pm 0.09$ & $0.35 \pm 0.08$ \\
Tyrosine & $0.19 \pm 0.05$ & $0.27 \pm 0.05$ & $0.34 \pm 0.08$ \\
Lysine & $0.29 \pm 0.07$ & $0.39 \pm 0.06$ & $0.61 \pm 0.11$ \\
Glycine & $0.20 \pm 0.05$ & $0.30 \pm 0.06$ & $0.41 \pm 0.09$ \\
Phenylalanine & $0.23 \pm 0.05$ & $0.27 \pm 0.06$ & $0.40 \pm 0.06$ \\
\hline
\end{tabular}

Tab. 4. Effect of relating urinary excretion parameters to creatinine on the variation coefficients (mean \pm SEM).

\begin{tabular}{|c|c|c|c|c|c|c|}
\hline & \multicolumn{2}{|l|}{$24 \mathrm{~h}$} & \multicolumn{2}{|l|}{$12 \mathrm{~h}$ day } & \multicolumn{2}{|l|}{$12 \mathrm{~h}$ night } \\
\hline & amount & $\begin{array}{l}\text { amount } \\
\text { per creatinine }\end{array}$ & amount & $\begin{array}{l}\text { amount } \\
\text { per creatinine }\end{array}$ & amount & $\begin{array}{l}\text { amount } \\
\text { per creatinine }\end{array}$ \\
\hline Albumin & $0.76 \pm 0.08$ & $0.79 \pm 0.08$ & $0.87 \pm 0.12$ & $0.84 \pm 0.12$ & $0.96 \pm 0.17$ & $1.10 \pm 0.16$ \\
\hline Sodium & $0.34 \pm 0.06$ & $0.34 \pm 0.03$ & $0.47 \pm 0.09$ & $0.43 \pm 0.04$ & $0.48 \pm 0.06$ & $0.37 \pm 0.04$ \\
\hline Potassium & $0.38 \pm 0.03$ & $0.33 \pm 0.03$ & $0.44 \pm 0.07$ & $0.38 \pm 0.03$ & $0.53 \pm 0.05$ & $0.36 \pm 0.08$ \\
\hline Aspartic acid & $0.35 \pm 0.06$ & $0.29 \pm 0.08$ & $0.37 \pm 0.01$ & $0.34 \pm 0.04$ & $0.54 \pm 0.09$ & $0.36 \pm 0.10$ \\
\hline Serine & $0.44 \pm 0.12$ & $0.28 \pm 0.04$ & $0.59 \pm 0.15$ & $0.42 \pm 0.02$ & $0.46 \pm 0.03$ & $0.30 \pm 0.01$ \\
\hline Tyrosine & $0.41 \pm 0.01$ & $0.32 \pm 0.01$ & $0.41 \pm 0.03$ & $0.31 \pm 0.02$ & $0.60 \pm 0.01$ & $0.39 \pm 0.05$ \\
\hline Lysine & $0.75 \pm 0.04$ & $0.67 \pm 0.18$ & $0.91 \pm 0.25$ & $0.80 \pm 0.18$ & $0.90 \pm 0.06$ & $0.80 \pm 0.12$ \\
\hline Glycine & $0.33 \pm 0.01$ & $0.32 \pm 0.01$ & $0.41 \pm 0.01$ & $0.38 \pm 0.02$ & $0.52 \pm 0.01$ & $0.42 \pm 0.03$ \\
\hline Phenylalanine & $0.41 \pm 0.10$ & $0.30 \pm 0.07$ & $0.46 \pm 0.14$ & $0.32 \pm 0.07$ & $0.58 \pm 0.06$ & $0.36 \pm 0.04$ \\
\hline
\end{tabular}


Tab. 5. Correlation of excretion parameters (mean of correlation values from days $0,1,14$ and 28 of the study).

\begin{tabular}{llll}
\hline & $24 \mathrm{~h} / 12 \mathrm{~h}$ day & $24 \mathrm{~h} / 12 \mathrm{~h}$ night & $12 \mathrm{~h}$ day/12 h night \\
\hline Water & 0.75 & 0.60 & 0.25 \\
Creatinine & 0.71 & 0.59 & 0.24 \\
Sodium & 0.68 & 0.64 & 0.08 \\
Potassium & 0.92 & 0.54 & 0.28 \\
Chloride & 0.72 & 0.44 & 0.21 \\
Immunoglobulin G & 0.75 & 0.63 & 0.42 \\
Albumin & 0.90 & 0.75 & 0.36 \\
$\alpha_{1}$-Glycoprotein & 0.94 & 0.62 & 0.22 \\
Lysozyme & 0.67 & 0.67 & 0.42 \\
$\beta_{2}$-Microglobulin & 0.89 & 0.78 & 0.45 \\
Alkaline phosphatase & 0.91 & 0.78 & 0.21 \\
$\gamma$-Glutamyltransferase & 0.86 & 0.43 & 0.25 \\
N-Acetyl- $\beta$ - $D$-glucosaminidase & 0.79 & 0.73 & 0.21 \\
Aspartic acid & 0.66 & 0.86 & 0.33 \\
Serine & 0.81 & 0.80 & 0.29 \\
Tyrosine & 0.68 & 0.89 & 0.39 \\
Lysine & 0.83 & 0.83 & 0.12 \\
Glycine & 0.69 & 0.75 & 0.25 \\
Phenylalanine & 0.73 & 0.84 & \\
\hline
\end{tabular}

The aim of such urine screening is the monitoring of kidney function. Unlike investigations of kidney physiology under steady state conditions, data from outdoor volunteers also depend on day to day differences regarding the intake of fluid and electrolytes. Protein excretion depends on physical activity and blood pressure (4-6). Accordingly, data on the respective variations are needed to define criteria of kidney dysfunction for the collection period used in pharmacological studies. The smallest variation of the data was found in the 24 hour samples. Sampling in the night at rest did not decrease the variation compared with sampling during the day with more physical activity and food intake. In general, shortening the collection time increased the variation.

Larger amounts of water, electrolytes and proteins were excreted during the day, constituting the major part of the 24 hour quantity. The correlation of day and 24 hour urine constituents was thus higher than the correlation of night and 24 hour urines. The lack of correlation between the active day period and the resting night period shows that diurnal and nocturnal excretions are determined by different factors. In the case of amino acids, where day and night excretions did not differ, similar correlations were found between 24 hour and day or night collection periods.

When the quantities of electrolytes, proteins, and amino acids in the urines were related to the glomerular filtration, represented by urine creatinine, there was only an improvement of the variation of urinary amino acid excretion. The variation of protein and electrolyte excretion was not consistently improved.

Our data clearly favour the 24 hour collecting period because of the lower variation. On the other hand, urine collected at night may be useful for studies of metabolism under resting conditions, though it might not indicate possible malfunction under increased activity during the day. Day urine may reflect more accurately metabolic changes due to drug pharmacokinetics, since drug intake usually occurs in the daytime.

\section{Acknowledgement}

The authors wish to thank Mr. Andreas Rynk and Mrs. Monika Melchin for excellent technical assistance.

\section{References}

1. Wetzels, J. F., Hafkenscheid, J. C., Hessels, M., Hoitsma, A. J. \& Koene, R. A. (1988) Renal clearance of pancreatic and salivary amylase relative to creatinine clearance in patients with renal disease and proteinuria. Clin. Chem. 34, 589-591.

2. Tiel, U., Heilmann, P., Rejaibi, R. \& Schöneshöfer, M. (1989) Urinary oestriol-16-glucoronide determined by "on-line" liquid chromatography. J. Clin. Chem. Clin. Biochem. 27, 205-209.

3. Petersen, K.-G., Schultheiss, M., Rosack, C., Schuler, G., Khalaf, N., Schmidt, P., Hecker, W., Hang, H. \& Kerp, L. (1989) Diabetic proteinuria - What do marker proteins convey? Akt. Endokrinol. Stoffw. 10, 58-62.

4. Irving, R. A., Noakes, T. D., Irving, G. A. \& van Zyl-Smit, $R$. (1986) The immediate and delayed effects of marathon running on renal function. J. Urol. 136, 1176-1180.

5. Poortmans, J. R. \& Labilloy, D. (1988) The influence of work intensity on postexercise proteinuria. Eur. J. Appl. Physiol. 57, 260-263.

6. Alvestrand, A., Gutierrez, A., Bucht, H. \& Bergstrom, J. (1988) Reduction of blood pressure retards the progression of chronic renal failure in man. Nephrol. Dial. Transplant. 3, 624-631.

Prof. Karl-Georg Petersen

Abteilung Klinische Endokrinologie

Med.-Univ.-Klinik

Hugstetter Straße 55

W-7800 Freiburg : :

Eur. J. Clin. Chem. Clin. Biochẹm. / Vol. 29, 1991 / No. 3 